\title{
Diálogos possíveis entre educação antirracista e decolonial: vozes insurgentes, pedagogias críticas e a Lei 10.639/03
}

Diego dos Santos Reis* Maria da Glória Calado**

\begin{abstract}
Resumo:
O artigo tem por objeto discutir os diálogos possíveis entre a perspectiva decolonial e a proposição de uma educação antirracista. Busca-se retraçar, brevemente, o percurso dos embates e das negociações envolvidas na promulgação da Lei 10.639/03, sobretudo no que concerne à luta e ao protagonismo do movimento negro. Trata-se de analisar de que modo as práticas e as legislações antirracistas redefinem os itinerários de formação docente e impactam nos trajetos curriculares de estudantes e professores/as -, com consequências políticas e epistemológicas notórias. Por fim, são apresentados os desafios atuais para o combate ao racismo nas escolas, com ênfase nas vozes insurgentes e contracoloniais, no letramento racial crítico e nas práticas antirracistas.
\end{abstract}

\section{Palavras-chave:}

Educação antirracista. Decolonialidade. Lei 10.639/03. Letramento racial crítico. Movimento negro.

\begin{abstract}
:
The article aims to discuss the potential dialogues between the decolonial perspective and the proposal for an anti-racist education. It seeks to retrace, in brief, the course of the clashes and negotiations involved in the enactment of Law 10.639/03, especially with regard to the struggle and the protagonism of the Black Movement. It is about to analyze how the anti-racist practices and
\end{abstract}

\footnotetext{
* Professor Adjunto de Filosofia da Educação da Universidade Federal da Paraíba. Professor Colaborador do Programa de Pós-Graduação Humanidades, Direitos e Outras Legitimidades (Diversitas/FFLCH/USP). Pós-doutorando na Faculdade de Educação da Universidade de São Paulo. Doutor, mestre e licenciado em Filosofia pela Universidade Federal do Rio de Janeiro, com estágio doutoral no Institut d'Études Politiques de Paris (SciencesPo) (com bolsa CAPES/PDSE). Especialista em Epistemologias do Sul pelo Conselho Latino-Americano de Ciências Sociais (CLACSO). E-mail: diegoreis.br@gmail.com. ORCID iD: https://orcid. org/0000-0001-6977-7166.

** Professora do Centro Universitário SENAC. Professora convidada dos cursos de pós-graduação do Centro de Estudos Latino-Americanos sobre Cultura e Comunicação (CELACC/USP). Psicóloga clínica e psicóloga voluntária no Centro de Direitos Humanos de Sapopemba (CDHS - SP). Doutora em Educação pela Faculdade de Educação da Universidade de São Paulo. Mestra e graduada em Psicologia pela Universidade São Marcos. Participante da Rede de Proteção e Resistência contra o Genocídio, do grupo de pesquisa Movimentos Sociais, Comunicação, Cultura e Território na América Latina (CELACC/USP) e do grupo Mães em Luto da Zona Leste. E-mail: professoramgloria@gmail.com. ORCID iD: https://orcid.org/0000-0002-7885-4095.
} 
legislation redefine teacher training itineraries and impact curricular paths - of students and teachers - with remarkable political and epistemological consequences. Finally, the current challenges for combating racism in schools are presented, focused on the insurgent and counter-colonial voices, critical racial literacy and anti-racist practices.

\title{
Keyword:
}

Anti-racist education. Decoloniality. Law 10.639/03. Critical racial literacy. Black movement.

\begin{abstract}
"Ao colonialismo não basta encerrar o povo em suas malhas, esvaziar o cérebro colonizado de toda forma e todo conteúdo. Por uma espécie de perversão lógica, ele se orienta para o passado do povo oprimido, deforma-o, desfigura-o, aniquila-o."
\end{abstract}

Frantz Fanon

\section{Introdução}

As agendas e os desafios que envolvem a Educação para as Relações Étnico-Raciais têm pautado, nos últimos anos, o debate educacional sobre enfrentamento ao racismo nas escolas, nos currículos e na formação docente. Desafios que se apresentam não apenas à Educação, mas a diversos campos e instituições, instados a discutir questões concernentes à justiça racial, epistêmica e social, bem como ao genocídio negro em curso no Brasil, fruto do racismo estrutural, (re)produzido também no interior das instituições educacionais.

Diante das disputas e lutas pela efetivação de direitos fundamentais, o movimento negro brasileiro não cessou de indagar discursos hegemônicos e narrativas únicas, que respaldam violências e reforçam matrizes de dominação com recortes de classe, gênero e raça. No campo da Educação, a construção de pedagogias antirracistas, decoloniais e interculturais tem sido outro desafio em face ao recrudescimento da onda conservadora e antidemocrática no Brasil e no mundo. Debates relacionados às relações raciais, às questões de gênero e às desigualdades educacionais multiplicam-se em contextos marcados por refluxos democráticos, discursos de ódio e violações sistemáticas de direitos, que determinam quem pode viver e quem deve morrer - ou, ainda, quais corpos são violáveis no Brasil.

Nos antípodas das múltiplas hierarquizações do humano, que definem quais corpos são mais propensos às violências, a reflexão acerca da educação antirracista e das relações raciais no país deve iluminar não apenas as fissuras que cindem as gramáticas normativas e os campos em disputa, mas também os enfrentamentos plurais em nome de outros projetos de vida e de justiça racial/social/epistêmica. Nesse sentido, aqui são tecidas algumas considerações críticas, com vistas a analisar os diálogos possíveis entre a perspectiva decolonial e a proposição de uma educação antirracista. Enfatizam-se o letramento racial crítico para promoção de práticas antirracistas e a necessidade da efetiva implementação do disposto na Lei $10.639 / 03^{1}$, para reorientação de imaginários, bibliotecas e gramáticas, no sentido de promover uma repactuação dos termos e dos temas, de modo a contribuir para descolonização dos currículos, das práticas pedagógicas e dos saberes escolarizados. 


\section{O movimento negro e a implementação da Lei 10.639/03: uma história de lutas}

Sancionada pela Presidência da República em janeiro de 2003, a Lei 10.639/03, que alterou a Lei de Diretrizes e Bases da Educação Nacional (LDB), é resultado de um intenso processo de lutas e reivindicações do movimento negro. Alçada à bandeira precípua de luta, em nome de um projeto emancipatório, a educação converte-se em agenda fundamental das ações coletivas, a exemplo do que ocorreu com iniciativas como a Frente Negra Brasileira (FNB) e o Teatro Experimental do Negro (TEN). Como destacaria Nilma Lino Gomes, a educação é compreendida pelo movimento negro como um direito conquistado no cerne da luta pela democracia, "como aposta na produção de conhecimentos que valorizem o diálogo entre os diferentes sujeitos sociais e suas culturas e com espaço de formação de cidadãos que se posicionem contra toda e qualquer forma de discriminação" (GOMES, 2012a, p. 735).

Em face dessas tensões, apontando nas tendências conservadoras o seu viés racista e discriminatório, diversas mobilizações por uma educação antirracista foram desencadeadas como forma de enfrentamento à persistência de uma ideologia racialista (MUNANGA, 2004), a qual se baseia em uma perspectiva de hierarquização entre raças e saberes no campo educacional. Essa perspectiva não está dissociada do imaginário historicamente construído sobre o negro, que culmina por enquadrá-lo como ser primitivo, selvagem ou infantilizado, e suas práticas e saberes como epistemicamente desqualificados.

Evidentemente, esse ideário se refletiu no estabelecimento de uma polarização, com ensino elementar e profissional voltado para as classes populares e a educação científica e superior direcionada aos grupos pertencentes à elite. Desde o final do século XIX, com o medo de que o crescimento demográfico da população negra no pós-abolição representasse "um processo civilizatório africano provocado pelos negros que viviam no Brasil" (SILVA, 2009, p. 140), expressões discriminatórias, ora mais explícitas, ora mais veladas, não deixaram de se apresentar. Essas expressões pautavam-se em estereotipizações, que tinham por finalidade demarcar o lugar de inferioridade conferido aos negros e às culturas africanas:

[...] com a inculcação do estereótipo de inferioridade, o efeito pretendido é o de que o negro chegue a rejeição de si próprio, de seus assemelhados, de seus valores e sua cultura [...] o culto do modelo europeu branco com seu padrão estético, seus valores e sua cultura são reproduzidos pelos aparelhos ideológicos como a escola, igreja, família, etc., ao transmitirem a ideologia do dominador. (SILVA, 1997, p. 67).

O enfrentamento ao ideal salvacionista da branquitude - com a brancura concebida como virtude, saúde e força, ao passo que a negritude remetia ao primitivo, à indolência, à degeneração -, bem como ao eurocentrismo presente no meio educacional, vigente nas políticas educacionais brasileiras da primeira metade do século XX, postulava-se como uma tarefa cada vez mais urgente na luta antirracista. Isso porque as políticas eugenistas e de embranquecimento cultural produziam efeitos concretos, que resultavam não apenas na desigualdade educacional racialmente informada entre pessoas brancas e negras, mas na exclusividade de repertórios branco-europeus das instituições de ensino, eleitos como superiores pelo Estado (DÁVILA, 2006).

Desse modo, a resistência à ideologia do embranquecimento foi engendrada por diferentes movimentos negros ao longo do século XX. De modo geral, as manifestações de resistência negra se referiam à "luta dos negros na perspectiva de resolver seus problemas na sociedade abrangente, em particular os provenientes dos preconceitos e das discriminações raciais, que os marginalizam no mercado de trabalho, no sistema educacional, político e social e cultural" (DOMINGUES, 2007, p. 100).

Por parte da Frente Negra Brasileira (FNB), fundada em 1931, a produção do periódico $A$ Voz da Raça funcionou como espaço de debate e de circulação de ideias, que demonstravam a nítida preocupação com a educação da população negra no país. A FNB foi responsável pela fundação de escolas primárias e pela manutenção de cursos de alfabetização de adultos, de formação social, secundária e comercial. A partir da década de 1940, desenvolve-se o movimento social de négritude, inspirado por intelectuais africanos de língua francesa da diáspora, sobretudo Aimé Césaire e Léopold Senghor. A proposta consistia em afirmar 
uma estética negra, por meio da história, da cultura e dos símbolos africanos, como forma de resistir às políticas de embranquecimento e promover experiências estéticas ligadas à negritude. Tratava-se, portanto, de romper com as formas de assimilação e negação da cultura negra, tensionando padrões estéticos de beleza eurocentrados.

Ainda na década de 1940, dentre as organizações que realizavam ações coletivas para a garantia de direitos da população negra, faz-se necessário destacar o papel fundamental desempenhado pelo Teatro Experimental do Negro (TEN), fundado por Abdias Nascimento (DOMINGUES, 2007). Definida como uma das prioridades do grupo no combate ao racismo, a educação envolvia processos formativos diversos, compreendendo palestras, cursos de alfabetização para moradores de favelas, operários, empregadas domésticas e pessoas provenientes das classes empobrecidas. Além disso, a defesa do direito ao ensino universal e gratuito, bem como a "admissão subvencionada de estudante negro nas instituições de ensino secundário e universitário" (SISS, 2003, p. 51), faziam parte das pautas de lutas do TEN, que tem na fundação do Instituto Nacional do Negro, do Museu do Negro e na organização do I Congresso do Negro Brasileiro algumas de suas realizações mais emblemáticas.

Decorridas quase duas décadas de atuação pela emancipação e pela plena cidadania negra no Brasil, a extinção do TEN coincide com o Golpe Militar de 1964. Quatro anos depois, em 1968, Abdias Nascimento é coagido ao autoexílio. Durante o período ditatorial brasileiro, ocorreram perseguições a militantes negros e censuras a mobilizações contra o racismo, já que, na perspectiva do regime empresarial-militar, o racismo não existia na sociedade brasileira (DOMINGUES, 2007).

Dentre as formas de resistência que emergem no período ditatorial, pode-se mencionar, a título de exemplo, a fundação de periódicos voltados à comunidade negra, o desenvolvimento do movimento Soul posteriormente nomeado como Black Rio -, a criação do Instituto de Pesquisa de Culturas Negras (IPCN - RJ) e a formação do Centro de Cultura e Arte Negra (CECAN - SP), iniciativa de estudantes e artistas negros. Cabe ressaltar ainda o surgimento do Grupo Palmares (Porto Alegre, RS), que se notabilizou como o primeiro no país a defender a comemoração da Consciência Negra em 20 de novembro, data da morte de Zumbi dos Palmares, e não em 13 de maio.

Em 1978, a criação do movimento negro Unificado contra a Discriminação Racial (MNUCDR), cujo nome foi reduzido para movimento negro Unificado (MNU), marca uma etapa importante na organização e no aquilombamento da comunidade negra. O marco histórico remonta a uma manifestação, no centro de São Paulo, que reuniu cerca de três mil pessoas no Teatro Municipal da capital paulista. Para Domingues (2007), este movimento foi fortemente influenciado pelos movimentos internacionais em curso e pelas circunstâncias políticas internas. O MNU é impulsionado, notoriamente, pelo movimento de reivindicação por direitos civis nos Estados Unidos e por movimentos de descolonização em nações africanas, como Guiné-Bissau, Moçambique e Angola, além da Convergência Socialista, organização que existiu no Brasil entre 1978 e 1992. A conjugação de tais fatores e a luta pela igualdade racial levou o MNU a assumir um discurso incisivo contra o racismo, juntamente à luta contra o sistema capitalista, a partir da compreensão de que o capitalismo beneficia-se e apoia-se na lógica do racismo.

O Movimento defendia, assim, que a superação dos preconceitos e discriminações raciais só seria viável e efetiva a partir da construção de uma outra formação social e econômica, caracterizada pela justiça e igualdade racial. Para alcançar tal objetivo, a educação seria um caminho fundamental, pois, na perspectiva do MNU, era preciso atuar de modo decisivo para a:

[...] desmistificação da democracia racial brasileira; organização política da população negra; transformação do Movimento Negro em movimento de massas; formação de um amplo leque de alianças na luta contra o racismo e a exploração do trabalhador; organização para enfrentar a violência policial; organização nos sindicatos e partidos políticos; luta pela introdução da História da África e do Negro no Brasil nos currículos escolares, bem como a busca pelo apoio internacional contra o racismo no país. (DOMINGUES, 2007, p. 114, grifos nossos). 
O trecho destacado explicita, de forma embrionária, a reivindicação que se consolidará na letra da Lei no 10.639 (BRASIL, 2003), no que concerne aos currículos escolares, a partir da perspectiva do movimento negro. A luta pela inclusão de temas relacionados às culturas africanas e afro-brasileiras nas escolas ganha ainda mais força na década de 1990, em especial quando o Movimento organiza a "Marcha Zumbi dos Palmares contra o Racismo, pela Cidadania e a Vida", que reuniu 30 mil pessoas em 1995, à ocasião da celebração dos 300 anos de Zumbi, em Brasília. O evento ficou marcado pela entrega do "Programa para a Superação do Racismo e da Desigualdade Social" (GOMES, 2009) ao presidente da República à época, Fernando Henrique Cardoso. Um ano depois seria criado o Grupo de Trabalho Interministerial para a Valorização da População Negra. Dentre as medidas elaboradas nesse período, cabe destacar a promulgação da Lei de Diretrizes e Bases da Educação Nacional (Lei 9.394/1996) e a formulação dos Parâmetros Curriculares Nacionais (PCN), que refletem também os compromissos assumidos pelo Brasil na Conferência Mundial sobre Educação para Todos, ocorrida na Tailândia, em 1990 (GOMES, 2009).

A participação ativa desses movimentos sociais na cena pública viabilizou uma série de conquistas efetivas e avanços no âmbito da Educação, que conduzirão à formulação da Lei 10.639/03. Nesse sentido, cabe mencionar a inclusão do tema transversal "pluralidade cultural" nos PCNs de 1997, que indica a importância de se contemplar diversas culturas nos projetos didático-pedagógicos da escola brasileira. Souza (2001), entretanto, alerta para o fato de que o termo pluralidade aparece de forma difusa nos PCNs, já que negros e indígenas são colocados no mesmo patamar, desconsiderando-se especificidades culturais e, por vezes, dando a impressão de folclorização desses povos. A autora atenta também para o fato de que "ali [nesse documento], apesar das críticas ao longo dos últimos anos, pode-se identificar o mito da democracia racial. É a ideia de que no Brasil não há preconceito. Todos são iguais, têm os mesmos direitos" (SOUZA, 2001, p. 55).

No início dos anos 2000, outro evento ganha relevância no caminho para a conquista de uma legislação de enfrentamento ao racismo. A Conferência de Durban (CARNEIRO, 2002), que reuniu diversos/as intelectuais e representantes políticos, com patrocínio da Organização das Nações Unidas (ONU), teria como um de seus principais objetivos o incentivo à implementação de políticas públicas de combate ao racismo, à discriminação racial, à xenofobia e outras discriminações correlatas. No âmbito da Educação, o relatório da conferência engloba mais de quinze pontos, que serão fundamentais para as discussões travadas em torno da Lei 10.639/03. Os tópicos incluíam a questão do desenvolvimento de programas culturais e educacionais; a implementação de programas de educação formal e informal - em diálogo com organizações de jovens; a recomendação de elaboração de materiais didáticos antirracistas; e o incentivo à cooperação com órgãos internacionais, organizações não-governamentais e setor privado no combate ao racismo, com a participação ativa do MNU. Conforme explicita Petronilha Beatriz Gonçalves e Silva ${ }^{2}$, em entrevista à Rute Pina:

Em discussão com o Movimento Negro, se havia concluído que, para reeducar as relações étnico-raciais de forma a combater o racismo, seria necessário conhecer, estudar, aprender sobre a história e cultura dos povos que vieram da África e sobre a história e a cultura que produzem seus descendentes. Então, em novembro de 2002, começamos a trabalhar neste sentido. [...] Quando a Lei 10.639 foi promulgada, já havia um movimento para que se trabalhasse a educação étnico-racial a partir do conhecimento da história e da cultura afro-brasileira e africana. (PINA, 2017).

É necessário reconhecer, portanto, que os movimentos sociais negros - e, em especial, o MNU desempenharam um papel central na elaboração de práticas e legislações antirracistas, como as Diretrizes Curriculares Nacionais para a Educação das Relações Étnico-Raciais e para o Ensino de História e Cultura

2. A Prof. a Dra. Petronilha Beatriz Gonçalves e Silva é referência nacional em Educação para as Relações Étnico-Raciais (ERER) e relatora do Parecer no 003/2004 e da Resolução no 1/2004, do Conselho Nacional de Educação, que instituem as Diretrizes Curriculares Nacionais para a Educação das Relações Étnico-Raciais e para o Ensino de História e Cultura Afro-brasileira e Africana, documento orientador para a implementação da Lei 10.639/03. 
Afro-brasileira e Africana (BRASIL, 2004), no campo da Educação. Desse modo, a promulgação da Lei 10.639/03 concretiza-se como conquista fundamental para a descolonização de saberes e representações negros, bem como para a superação do epistemicídio e do racismo em território nacional.

\title{
Colonialidade do saber, epistemicídio e racismo epistêmico
}

A trajetória de lutas do MNU evidencia os árduos caminhos percorridos para implementação de políticas públicas no campo da Educação, em consonância com as pautas e agendas do Movimento. Ao disputar as concepções de educação e de conhecimento, tal como praticados pela racionalidade hegemônica ocidental, os movimentos sociais desafiam e ampliam noções estritas (e estreitas) segundo as quais o conhecimento científico produzido pelas instituições acadêmicas constitui-se como a única forma válida/ verdadeira de conhecimento. O movimento negro, ao questionar na cena pública o racismo brasileiro e as desigualdades raciais, indaga as relações de poder enraizadas em instituições, em estruturas estatais e em práticas cotidianas disseminadas por todo país, que não podem justificar-se no âmbito dos processos institucionais de educação senão pela via do racismo epistêmico. De acordo com Grosfoguel:

\begin{abstract}
O racismo epistêmico refere-se a uma hierarquia de dominação colonial por meio da qual o conhecimento produzido por sujeitos ocidentais (imperialistas e oprimidos) na zona do ser é considerado a priori como superior ao conhecimento produzido por sujeitos coloniais não-ocidentais na zona do não-ser [...], considerado universal e válido para todos os contextos e situações do mundo. (GROSFOGUEL, 2011, p. 102, tradução nossa).
\end{abstract}

Não estranha que uma das marcas principais da colonização seja, como destacou Césaire (1978, p. 26), milhões de seres humanos "a quem inculcaram sabiamente o medo, o complexo de inferioridade, o tremor, a genuflexão, o desespero, o servilismo". Essa violência múltipla - física e simbólica - objetiva submeter os sujeitos designados como racialmente inferiores à zona de não-ser (FANON, 2008), domesticados e subalternizados, pela via do trabalho e da educação, às "virtudes civilizacionais eurocêntricas".

As lutas contra as opressões e as desigualdades raciais, assim, são indissociáveis do questionamento das matrizes epistêmicas mobilizadas para justificá-las, bem como da afirmação de novas formas de saberes assentadas em lógicas não eurocêntricas e não ocidentais. Como sublinha Nilma Lino Gomes (2011), enquanto sujeitos políticos, os movimentos sociais produzem, acumulam e socializam conhecimentos, sendo as suas próprias lutas consideradas como processos formativos e vivências formadoras que questionam os pilares da racionalidade hegemônica.

Ao eleger a questão da Educação como uma de suas pautas fundamentais - e campo permanente de conflitos, tensões e de lutas -, o movimento negro brasileiro ampliou a conscientização da sociedade pela garantia dos direitos sociais, da justiça e das políticas de promoção da igualdade racial, indissociáveis da luta por uma sociedade efetivamente democrática. Nesse processo de negociação por direitos, ressignificação de discursos e desconstrução de representações negativas e práticas racistas, o movimento negro produz reorganização da ciência e dos saberes na construção de estratégias de resistência, atravessadas pelo potencial emancipatório da educação.

Assim, segundo Gomes (2011, p. 135), "enquanto sujeito político, esse movimento produz discursos, reordena enunciados, nomeia aspirações difusas ou as articula, possibilitando aos indivíduos que dele fazem parte reconhecerem-se nesses novos significados [produzidos]". E não só daqueles/as que estão mais diretamente implicados/as nas lutas do movimento, mas a todo o conjunto da sociedade e do Estado, que se encontram diante de demandas específicas dos diferentes grupos étnico-raciais e suas exigências reivindicatórias.

Nas trilhas de Paulo Freire, Gomes (2011) destaca que a Educação é entendida como parte essencial do processo de formação humana e fundamental para que se rompam "visões distorcidas, negativas e naturalizadas sobre os negros, sua história, sua cultura, práticas e conhecimento” (GOMES, 2018, p. 22). 
Ao destacar a necessidade de políticas educacionais específicas para os segmentos negros e para a tarefa urgente de descolonização dos currículos escolares, o movimento negro propõe não apenas forjar ferramentas efetivas de luta contra as desigualdades raciais e contra o racismo estrutural da sociedade brasileira, mas reposicionar as narrativas, as estéticas, os saberes político-identitários e interpretações acerca da trajetória do negro no Brasil. Daí a importância das práticas educativas, da mudança das representações ligadas à cultura negra e da inclusão de saberes africanos e afro-brasileiros nos currículos escolares, o que exige o "questionamento dos lugares de poder. Indaga a relação entre direitos e privilégios arraigada em nossa cultura política e educacional, em nossas escolas e na própria universidade" (GOMES, 2012b, p. 99).

A promulgação da Lei 10.639/03, nesse sentido, representa um passo importante para ampliação do compromisso institucional, configurado como política de Estado, com premissas fundamentais para a agenda da igualdade racial. A articulação da questão racial com a Educação e a História possibilita não apenas que os currículos e conteúdos sejam revistos, malgrado a sua relevância incontestável. É o processo formativo e suas instituições, em sua integralidade, que são tensionados e instados a serem repensados, com vistas a pautar também demandas e perspectivas negras, essenciais na luta pela descolonização do saber e de suas representações.

Desafiar as hierarquias epistêmicas e os postulados ocidentalcêntricos é tarefa incontornável na construção da justiça cognitiva ${ }^{3}$ (SANTOS, 2006) e racial, na medida em que "a colonialidade é um dos elementos constitutivos e específicos do padrão mundial do poder capitalista. Se funda na imposição de uma classificação racial/étnica da população mundial como pedra angular deste padrão de poder" (QUIJANO, 2007, p. 93). Daí, a perspectiva decolonial redimensionar a questão colonial, apontando no apagamento das produções de matrizes africanas e afro-brasileiras os rastros e as permanências do racismo, do colonialismo e do patriarcalismo, que configuram a economia dos saberes globais. A universalidade dos padrões hegemônicos culmina por suplantar as culturas locais/tradicionais, impondo a elas os critérios valorativos eurocentrados.

É nos termos do epistemicídio que Sueli Carneiro irá denunciar esse procedimento de sistemática aniquilação subjetiva e epistêmica de sujeitos sufocados pelas tramas coloniais:

Sendo, pois, um processo persistente de produção da inferioridade intelectual ou da negação da possibilidade de realizar as capacidades intelectuais, o epistemicídio nas suas vinculações com as racialidades realiza sobre seres humanos instituídos como diferentes e inferiores uma tecnologia que integra o dispositivo de racialidade/biopoder, e que tem por característica específica compartilhar características tanto do dispositivo quanto do biopoder, a saber, disciplinar/normatizar e matar ou anular. (CARNEIRO, 2005, p. 97).

O engajamento da intelectualidade negra, nesse sentido, materializa as premissas das lutas contra a violência racial, os processos coloniais e as dinâmicas opressivas que tomam por alvo preferencial o corpo negro. Ao questionar identidades, memórias e o lugar do negro, aponta-se para o território de uma dupla experiência a ser reconhecida: de um corpo, simultaneamente, colonizado pela cultura hegemônica e da submissão imposta à população negra às representações redutoras de um olhar que a enquadra como destituída de agência. Ademais, coloca-se em questão o sistema de gênero/sexualidade, com suas intersecções, cujas representações reiteram papéis subalternizados e objetificados, compulsoriamente conferidos aos corpos femininos, com maior virulência orientada às mulheres negras - hiperssexualizadas e animalizadas.

Interrogar o (não-)lugar da mulher racializada nas epistemologias eurocêntricas e os paradigmas de conhecimento sustentados por elas significa atentar para os processos de invisibilização, silenciamento e

\footnotetext{
3. Para Santos (2006), a justiça cognitiva está assentada no tratamento igualitário a distintas matrizes epistêmicas e formas de saberes, de modo a desfazer hierarquizações, desigualdades e assimilações excludentes impostas a seres e saberes pelos processos coloniais. A defesa da diversidade epistêmica, porém, não se reduz ao campo epistemológico. A luta pela diversidade epistêmica está ligada ao reconhecimento, ao respeito e à valorização de modos de vida, práticas e experiências diversos, bem como à emancipação e à justiça social, na contraposição a valores ocidentais hegemônicos, a perspectivas monoculturais do ser/saber/viver e à marginalização de grupos sociais.
} 
aniquilamento subjetivo das mulheres negras, subjugadas, historicamente, pela violência colonial, racista e patriarcal. Aqui, a crítica colonial questiona as estruturas de poder fundadas no projeto moderno/colonial/ sexista/racista, para discutir os efeitos deletérios do racismo e do sexismo e os caminhos para sua superação.

Nesse contexto, a pedagogia decolonial (WALSH, 2007) tem por função colocar em xeque os imaginários, repertórios e bibliotecas ancorados em uma monocultura racional - racial e sexual -, que produz continuamente silêncios, lacunas e ausências. Superar os padrões de dominação da modernidade colonial requer reafirmar a existência e a validade dos saberes produzidos por sociedades extra-europeias, bem como de outras lógicas epistêmicas, que ultrapassam o modelo ocidental.

Trata-se de questionar as perspectivas interpretativas eurocentradas, mormente no que se refere à questão da raça e do racismo, tal como gestadas pela modernidade/colonialidade. Por conseguinte, a perspectiva decolonial reivindica uma lente de leitura que considere raça, gênero e classe como dimensões cruciais, interseccionadas, para a compreensão da hierarquização de humanidades que fundamenta a inferiorização dos povos dominados. O paradigma epistemológico da modernidade europeia, pautado na centralidade do discurso científico e na universalidade epistêmica do ocidente, opera de modo a invisibilizar a existência e a agência dos sujeitos que se encontram nas periferias da Europa. Por isso, a ideia de "raça" constitui-se como núcleo em torno do qual a narrativa europeia tratou de forjar um instrumento de diferenciação, voltado a justificar a dominação colonial e o poder cognitivo de uma forma exclusiva de conhecimento (QUIJANO, 2007; REIS, 2020b).

A teoria decolonial, ao afirmar o locus de produção do conhecimento e inseri-lo em uma história, aponta para a localização particular de sujeitos cujos discursos e experiências, longe da pretensa universalidade, são situados, isto é, marcados por lugares de enunciação singulares, geopoliticamente posicionados. A permanência colonial e o reiterado processo de silenciamento, precarização e aniquilamento das populações submetidas à empresa colonial desvelam a indissociabilidade entre o epistemicídio, que exclui saberes e lógicas não europeias, e a violência legitimada pelo não reconhecimento da humanidade de outros sujeitos.

Assim, opera-se não somente a invisibilização de quem se mata, mas produz-se o salvo conduto de quem aponta, em seu trabalho "humanitário", uma espécie de gesto pedagógico irrepreensível. O paradigma epistêmico ocidental reafirma-se pela promoção da homogeneização cultural e pela destituição de outras formas de pensamento, principalmente pela via de um "processo persistente de produção da indigência cultural” (MBEMBE, 2018, p. 97). A anulação sistemática da capacidade cognoscente dos povos não europeus, diante da matriz hegemônica do conhecimento difundido como superior, é naturalizada.

O racismo é, desse modo, o pilar de sustentação da instituição colonial. É na deslegitimação dos saberes e das práticas não ocidentais que vem se instalar - transplantada - uma cultura cuja autoimagem de universalidade republicana lhe outorga o direito de intervenção alhures (REIS, 2020a). Ao refirmar a racionalidade de seus discursos, para além do domínio mítico ou religioso, a história e a filosofia ocidentais passam a operar como centros positivados que excluem não só uma série de outros discursos distintos de suas lógicas, mas também funcionam como medição dos graus de racionalidade que definem quem é humano e quem não é. Por isso:

[...] o eurocentrismo torna-se, portanto, uma metáfora para descrever a colonialidade do poder, na perspectiva da subalternidade. Da perspectiva epistemológica, o saber e as histórias locais européias foram vistos como projetos globais, desde o sonho de um Orbis universalis christianus até a crença de Hegel em uma história universal, narrada de uma perspectiva que situa a Europa como ponto de referência e de chegada. (MIGNOLO, 2003, p. 41).

As lutas contracoloniais e antirracistas, portanto, encontram nas práticas insurgentes e emancipadoras das ações coletivas o seu ponto de tangência. Visa-se uma ação transformadora da sociedade como um todo, que promova um rearranjo das formas de organização social e das estruturas que sustentam a lógica colonial-racista persistente também nas práticas e nas instituições educativas. Se os currículos e as instituições educacionais são atravessados por conflitos e interesses os mais diversos, como intervenções que 
contestam a "epidermização dessa inferioridade" (FANON, 2008, p. 28), as proposições contra-hegemônicas emergem, sim, no chão da escola, mas miram horizontes que o transpassam e o extrapolam: o direito à vida, à justiça social, racial e cognitiva.

\section{Desafios para efetivação do letramento racial crítico na Educação Básica}

Não são poucos, todavia, os desafios para efetivação de práticas educativas que promovam um letramento racial crítico (SKERRETT, 2011) na Educação Básica. É manifesto que, para além da legislação, é preciso forjar instrumentos e práticas que implementem o disposto pela lei, a fim de fomentar uma educação antirracista nas escolas e fora delas. Metodologias e práticas pedagógicas são cruciais para que as atividades propostas pelos/as docentes sejam refletidas em espaços de discussão nos quais professoras/ es e estudantes possam ser transformados/as por meio de uma reorientação epistemológica que tensione e desconstrua os paradigmas vigentes.

Segundo Skerrett (2011, p. 314), o "letramento racial é uma compreensão das formas poderosas e complexas em que raça influencia as experiências sociais, econômicas, políticas e educacionais de indivíduos e grupos”. Na perspectiva de uma prática educativa antirracista, o letramento racial adquire lugar central na reconfiguração de relações e na desconstrução de padrões hegemônicos, reposicionando o lugar da escola como agência de letramentos implicada não só no exercício para a aquisição de determinados códigos - numérico, alfabético, escrito -, mas dos usos sociais e antirracistas que são feitos a partir deles.

A gramática instituída por essa prática exige, sem dúvida, que se compreenda o letramento racial crítico como exercício de leitura e escrita que supõe uma (re)visão de mundo. Práticas afrorreferenciadas repactuam o sistema de valores e de valorações, redimensionando modelos pautados pelos ideais civilizatórios da colonização, de base patriarcal-escravagista. Entender que a educação antirracista tem a função de desfazer político-pedagogicamente um projeto de Estado, historicamente ancorado em discursos, instituições e agências racistas, requer reposicionar o lugar da discussão racial em todas as esferas sociais e campos epistêmicos. Porque se o racismo estrutura todas as relações sociais e confere as bases de sustentação para que as dinâmicas desiguais se mantenham incontestes, a ruptura com esse sistema passa pela crítica à hierarquização racial e pela lógica eurocêntrica. Escancarar esse ideário, que pavimenta as relações de poder dentro e fora da escola, demanda explicitar o sustentáculo, institucional inclusive, que permite a produção e circulação de determinadas narrativas privilegiadas, enquanto invisibiliza a presença e silencia as vozes de sujeitos objetificados - negros, quilombolas, indígenas, periféricos -, expropriados de sua própria história.

O que um intelectual como Abdias Nascimento já apontava quando reivindica uma matriz teórica que não deixasse de oferecer subsídios para a construção de um movimento antirracista: “[...] os negros têm como projeto coletivo a ereção de uma sociedade fundada na justiça, nas igualdades e no respeito a todos os seres humanos, na liberdade: uma sociedade cuja natureza intrínseca torne impossível a exploração econômica e o racismo" (NASCIMENTO, 2002, p. 262).

Desse modo, a emergência de outros paradigmas para a prática docente, informados pela decolonialidade e pelo compromisso ético-político e epistêmico do letramento racial, possibilita a compreensão de "que não há hierarquias entre conhecimentos, saberes e culturas e sim uma história de dominação, exploração e colonização que deu origem a um processo de hierarquização de conhecimentos, culturas e povos" (GOMES, 2012a, p. 102). Com a desnaturalização de pressupostos históricos, políticos e raciais, reinscritos no seio da cultura, evidenciam-se projetos de sociedade distintos em disputa, além de uma estrutura de dominação geopolítica, ancorada no padrão mundial de poder fomentado pela colonialidade.

Em sociedades nas quais a branquitude é posicionada como norma, a formação hegemônica reitera as premissas fundadas nesse sistema de poder como normatividade do sistema educacional. O resultado, como se sabe, é que permanece inquestionada a racialidade branca, alçada à perspectiva privilegiada e modelo universalizado que informa relações sociais, políticas e epistêmicas segundo sua compreensão, situada em uma posição desigual de poder. Ao tematizar não só a negritude, mas a branquitude como construção 
social, histórica e cultural é preciso mapear o jogo de privilégios e prejuízos que conferem vantagens e maior número de oportunidades a sujeitos brancos, enquanto impõe barreiras materiais e simbólicas aos sujeitos não brancos, sob a frágil justificativa meritocrática.

Compreender a dimensão política dessas construções - negritude, branquitude, colonialidade -, em perspectiva antirracista e decolonial, implica na defesa de uma proposta pedagógica que problematiza "questões identitárias, como a ancestralidade, a resistência e a cultura, sugerindo para esses pilares a utilização de novas matrizes teóricas que contemplem outros olhares sobre o processo histórico da cultura afro-brasileira" (MOREIRA, 2019, p. 63). O diálogo entre as diferentes culturas, tradições e matrizes epistêmicas não se reduz a uma concepção meramente inclusiva, para expor, a partir de uma leitura exotizante, o que deve ser "tolerado". Salienta-se a importância, nesse contexto, da interculturalidade crítica como projeto político-pedagógico de descolonização dos olhares, das representações e dos currículos. Nas trilhas de Catherine Walsh:

A interculturalidade crítica [...] é uma construção de e a partir das pessoas que sofreram uma experiência histórica de submissão e subalternização. Uma proposta e um projeto político que também poderia expandir-se e abarcar uma aliança com pessoas que também buscam construir alternativas à globalização neoliberal e à racionalidade ocidental, e que lutam tanto pela transformação social como pela criação de condições de poder, saber e ser muito diferentes. Pensada desta maneira, a interculturalidade crítica não é um processo ou projeto étnico, nem um projeto da diferença em si. [...] é um projeto de existência, de vida. (WALSH, 2007, p. 8).

Como projeto de existência e de vida, desfazer hierarquias reproduzidas e naturalizadas pelo Estado e por suas instituições é primordial para que se avance nas lutas por justiça social/racial e epistêmica, nas quais a educação intercultural está implicada. A construção de pedagogias decoloniais, antirracistas e interseccionais é fundamental para o aprofundamento e ampliação do debate acerca da descolonização dos currículos e das práticas pedagógicas, respaldado por um letramento racial crítico. Sobretudo, em um contexto no qual, como denuncia Abdias Nascimento,

[o] sistema educacional funciona como aparelhamento de controle nesta estrutura de discriminação cultural. Em todos os níveis do ensino brasileiro - primário, secundário, universitário, o elenco das matérias ensinadas, como se executasse o que havia previsto a frase de Sílvio Romero, constitui um ritual da formalidade e da ostentação das salas da Europa, e, mais recentemente, dos Estados Unidos. Se consciência é memória e futuro, quando e onde está a memória africana, parte inalienável da consciência brasileira, no currículo escolar? Onde e quando a história da África, o desenvolvimento de suas culturas e civilizações, as características do seu povo, foram ou são ensinadas nas escolas brasileiras? (NASCIMENTO, 2016, p. 113).

Os desafios para as práticas de letramento racial na Educação Básica são inúmeros. A promulgação da Lei 10.639/03 não está dissociada, então, da necessidade de forjar estratégias conjuntas para que o dispositivo seja efetivamente implementado. A formação docente, a reorientação dos currículos e a responsabilidade estatal no cumprimento do dispositivo exigem que se assuma o compromisso ético-político de enfrentamento a um sistema excludente e discriminatório, eivado de contradições. Viabilizar processos formativos e práticas pedagógicas letradas racialmente é apostar na transformação de uma realidade estruturalmente desigual pela via de uma educação antirracista, afrorreferenciada e intercultural.

Como espaços plurais de construções coletivas, as instituições escolares podem e devem atuar para reposicionar a discussão acerca das relações étnico-raciais no Brasil, atentando para necessária repactuação epistemológica. O letramento racial crítico não se esgota, porém, na escola (FERREIRA, 2014). Ele deve ser estendido a todos os meios e ambientes sociais, explicitando a urgência do debate para compreensão da sociedade brasileira e suas contradições, bem como do racismo que pavimenta instituições, agências e relações sociais. 


\section{Combate ao racismo nas escolas}

A escola é um locus privilegiado de enfrentamento ao racismo. Para a superação do racismo, dentro e fora da escola, é preciso combater, sem concessões, olhares, práticas e representações racistas em todos os espaços sociais. Potencializar estratégias antirracistas na escola, em todos os níveis e etapas formativas, é fundamental para desnaturalizar e desconstruir os ideais de branquitude, desde a Educação Infantil, haja vista que, "nesse início de vida, a família e a escola serão os mediadores primordiais, apresentando/ significando o mundo social" (CAVALLEIRO, 1998, p. 19).

Apesar da posição elementar no combate às discriminações raciais, a escola também é espaço de (re) produção do racismo, tornando-se, muitas vezes, um ambiente hostil para crianças e adolescentes negros. Não é fortuito que, em pesquisa intitulada "Preconceito e Discriminação no Ambiente Escolar", realizada pela Fundação Instituto de Pesquisas Econômicas (FIPE), em 2009, mostrou-se que 99,3\% das pessoas entrevistadas explicitavam algum tipo de preconceito na escola. E os grupos mais passíveis de sofrerem preconceito eram aqueles de pessoas com deficiência (96,5\%) e pessoas negras (94,2\%) (CALADO, 2013).

Ao investigar estratégias de atuação antirracistas, Gomes (1999) aponta que muitos/as professores/as ainda consideram que a escola não é o espaço adequado para discutir as questões raciais, o que contribui para o silenciamento do debate. Gomes identifica nessa posição a concepção corrente sobre a função da escola, qual seja, exclusivamente a de transmissão dos conteúdos historicamente acumulados. Esses conteúdos, no entanto, argumenta Gomes, não podem ser trabalhados de maneira desvinculada da realidade social brasileira. Para que haja avanços nesse debate, é preciso que

[...] os(as) educadores(as) compreendam que o processo educacional também é formado por dimensões como a ética, as diferentes identidades, a diversidade, a sexualidade, a cultura, as relações raciais, entre outras. E trabalhar com essas dimensões não significa transformá-las em conteúdos escolares ou temas transversais, mas ter a sensibilidade para perceber como esses processos constituintes da nossa formação humana se manifestam na nossa vida e no próprio cotidiano escolar. Dessa maneira, poderemos construir coletivamente novas formas de convivência e de respeito entre professores, alunos e comunidade. É preciso que a escola se conscientize cada vez mais de que ela existe para atender a sociedade na qual está inserida e não aos órgãos governamentais ou aos desejos dos educadores. (GOMES, 1999, p. 147).

Nesse sentido, uma educação antirracista deve combater a denegação e, por consequência, o lastro de práticas racistas presentes nos currículos, Projetos Político-Pedagógicos (PPPs) e nas ações de educadores/ as e gestores/as escolares. Sabe-se que, apesar da vigência da Lei, esse papel ainda está concentrado nas iniciativas particulares de docentes e é quase inexistente nos PPPs das instituições educativas, conforme observa Petronilha Silva (PINA, 2017). Ademais, uma série de iniciativas antirracistas ainda são pontuais, restritas ao mês de novembro:

Há também professores que não se manifestam e outros que se dedicam apenas a algumas atividades e projetos restritos ao mês da Consciência Negra. O que temos que fazer é a avaliação da formação dos professores e também dos princípios que cada professor leva para sua docência: que tipo de projeto de sociedade cada professor está construindo. Os professores que lutam por uma sociedade democrática e igualitária evidentemente estão empenhados em trabalhar a educação das relações étnico-raciais por meio da cultura e história dos afro-brasileiros e africanos, bem como dos povos indígenas durante todo o ano. (PINA, 2017).

Nesse contexto, o/a professor/a é um/a agente que deve atuar na positivação da autoimagem das crianças e jovens negros/as, trabalhando na desconstrução de estigmas e estereótipos. Desse modo, romper com o apagamento negro-africano dos currículos e dos saberes escolarizados demanda confrontar as práticas racistas e tematizar a história e a cultura em perspectiva afrorreferenciada, em todos os componentes curriculares e espaçotempos educativos. 


\section{Por uma educação antirracista e contracolonial}

Diante das lutas e questionamentos do movimento negro, a escola, as instituições e a sociedade brasileira são impelidas a assumir um posicionamento pautado pelo compromisso de combate a práticas racistas e pela construção de projetos político-pedagógicos racialmente engajados. Junto à formulação de políticas públicas educacionais voltadas à superação das desigualdades raciais, por parte do Estado, as assimetrias intraescolares devem, igualmente, ser enfrentadas com determinação. Mas não é só isso. As disputas necessitam ser levadas a cabo no campo dos direitos (GOMES, 2010), com a exigência de transformações concretas e mecanismos garantidores, no âmbito jurídico, capazes de reorientar práticas e políticas educacionais.

Vê-se que as contradições e dilemas não se encerram somente na dificuldade de propor medidas em favor de uma educação antirracista e contracolonial. A dificuldade de tematizar e debater questões étnico-raciais na escola desvela a incapacidade de reconhecer a diversidade e de compreender a história da diáspora e da população negra no país, bem como do racismo estrutural e institucional, que organizam as relações sociais brasileiras. Práticas e imaginários racistas alijam do chão da escola uma série de saberes, experiências, valores e cosmopercepções racialmente informados. Tratar o tema exclusivamente do ponto de vista moral, de outro lado, reduzido a negações individuais, cuja finalidade é resguardar a "boa consciência" das pessoas que não se julgam racistas, é infecundo para avançar a discussão e a agenda antirracista no país.

É preciso, nesse horizonte, planejar ações e executá-las de forma responsável, de maneira resoluta. A responsabilização do Estado brasileiro e dos sujeitos que se beneficiam do pacto racial vigente no país, bem como a revisão crítica de saberes, narrativas e experiências de sujeitos inferiorizados racialmente, são premissas fundantes para qualquer mudança efetiva nas estruturas da sociedade brasileira. A escola e os agentes educativos devem assumir o compromisso com a desconstrução de estigmas, estereótipos raciais e sexuais e com a reversão do pacto narcísico da branquitude (BENTO, 2002) e da meritocracia. Superar esse quadro de desigualdade, em todos os níveis do processo de escolarização, demanda ação conjunta, planejamento e reflexão crítica no sentido de ampliar o alcance e o impacto das medidas antirracistas.

A Lei 10.639/03, como marco histórico dessas medidas, deve ser destacada como produto das lutas sociais, tendo suas proposições materializadas no Plano Nacional de Implementação das Diretrizes Curriculares Nacionais da Educação das Relações Étnico-Raciais e para o Ensino de História e Cultura Afro-brasileira e Africana (BRASIL, 2004), documento orientador para a implementação da referida Lei. Ao tensionar as estruturas vigentes, os movimentos sociais tornam visíveis as tramas e os traumas históricos, mas também o protagonismo de sujeitos cujas vidas são marcadas pelas lutas: constantes, radicais, inegociáveis. Em termos pedagógicos e epistemológicos, os desafios não são poucos. Redimensionar epistemicamente a lógica euro-ocidental em voga, apontando outras corpo-políticas do conhecimento, é fundamental para o processo de descolonização dos corpos e do pensamento. Daí, o pleito por uma educação antirracista, intercultural e contracolonial ser a pedra angular desse projeto pedagógico e social. Como propõe Walsh, a interculturalidade

[...] é central à (re)construção de um pensamento crítico-outro - um pensamento crítico de/desde outro modo -, precisamente por três razões principais: primeiro, porque está vivido e pensado desde a experiência vivida da colonialidade [...]; segundo, porque reflete um pensamento não baseado nos legados eurocêntricos ou da modernidade e, em terceiro, porque tem sua origem no sul, dando assim uma volta à geopolítica dominante do conhecimento que tem tido seu centro no norte global. (WALSH, 2005, p. 25).

Nessa perspectiva, diante de inúmeros dilemas, tensões e desafios, somos convocados/as a adotar uma postura de subversão do status quo e de enfrentamento radical às desigualdades, às hierarquizações e à inferiorização de humanidades que sustentam, historicamente, o projeto moderno/colonial/racista/ eurocêntrico/patriarcal/cisheteronormativo. Urge, assim, que possamos forjar e viabilizar uma educação antirracista, intercultural e contracolonial, voltada para emancipação social e para igualdade racial. Pois, 
sem assumir esse compromisso, a construção de qualquer sociedade verdadeiramente democrática será obstaculizada pelas barreiras de cor, que seguem funcionando como pedágio nas vias para o pedagógico.

\section{Referências}

BENTO, Maria Aparecida da Silva. Pactos narcísicos no racismo: branquitude e poder nas organizações empresariais e no poder público. 2002. Tese (Doutorado em Psicologia) - Instituto de Psicologia, Universidade de São Paulo, São Paulo, 2002.

BRASIL. Lei $n^{\circ} 10.639$, de 9 de janeiro de 2003. Altera a Lei ${ }^{\circ}$ 9.394, de 20 de dezembro de 1996, que estabelece as diretrizes e bases da educação nacional, para incluir no currículo oficial da Rede de Ensino a obrigatoriedade da temática «História e Cultura Afro-Brasileira», e dá outras providências. Diário Oficial da União: seção 1, Brasília, DF, p. 1, 10 jan. 2003. Disponível em: https://www.planalto.gov.br/ccivil_03/Leis/2003/L10.639.htm. Acesso em: 26 out. 2020.

BRASIL. Ministério da Educação. Plano Nacional de Implementação das Diretrizes Curriculares Nacionais da Educação das Relações Étnico-Raciais e para o Ensino de História e Cultura Afro-brasileira e Africana. Brasília, DF: MEC/ SECADI, 2004. Disponível em: http://etnicoracial.mec.gov.br/images/pdf/diretrizes_curric_educ_etnicoraciais.pdf. Acesso em: 11 ago. 2020.

CALADO, Maria da Glória. Escola e enfrentamento do racismo: as experiências das professoras ganhadoras do Prêmio Educar para a Igualdade Racial. 2013. Tese (Doutorado em Educação) - Faculdade de Educação, Universidade de São Paulo, São Paulo, 2013.

CARNEIRO, Aparecida Sueli. A batalha de Durban. Rev. Estud. Fem., Florianópolis, v. 10, n. 1, p. 209-214, jan. 2002.

CARNEIRO, Aparecida Sueli. A construção do outro como não-ser como fundamento do ser. 2005. Tese (Doutorado em Educação) - Faculdade de Educação, Universidade de São Paulo, São Paulo, 2005.

CAVALLEIRO, Eliane. Do Silêncio do Lar ao Silêncio Escolar: racismo, preconceito e discriminação na educação infantil. 1998. Dissertação (Mestrado em Educação) - Faculdade de Educação, Universidade de São Paulo, São Paulo, 1998.

CÉSAIRE, Aimé. Discurso sobre o colonialismo. Tradução de Noémia de Sousa. Lisboa: Sá da Costa Editora, 1978.

DÁVILA, Jerry. Diploma de Brancura: política social e racial no Brasil - 1917-1945. São Paulo: Editora UNESP, 2006.

DOMINGUES, Petrônio. Movimento Negro brasileiro: alguns apontamentos históricos. Tempo, Niterói, v. 12, n. 23, p. $100-122,2007$.

FANON, Frantz. Pele negra, máscaras brancas. Tradução de Renato da Silveira. Salvador: EDUFBA, 2008.

FERREIRA, Aparecida de Jesus (org.). As políticas do livro didático e identidades sociais de raça, gênero, sexualidade e classe em livros didáticos. Campinas: Pontes, 2014.

GOMES, Nilma Lino. Diversidade étnico-racial e educação no contexto brasileiro: algumas reflexões. In: GOMES, Nilma Lino. (org.). Um olhar além das fronteiras: educação e relações raciais. Belo Horizonte: Autêntica, 2010. p. 97-110.

GOMES, Nilma Lino. Educação e relações raciais: refletindo sobre algumas estratégias de atuação. In: MUNANGA, Kabengele (org.). Superando o racismo na escola. 2. ed. Brasília, DF: MEC/SECAD, 1999. p. 143-154.

GOMES, Nilma Lino. Limites e possibilidades da implementação da Lei 10.639/03 no contexto das políticas públicas em educação. In: PAULA, Marilene de; HERINGER, Rosana (org.). Caminhos convergentes: estado e sociedade na superação das desigualdades raciais no Brasil. Rio de Janeiro: Heinrich Böll Stiftung; Action Aid, 2009. p. 39-74.

GOMES, Nilma Lino. O Movimento Negro educador: saberes construídos nas lutas por emancipação. Petrópolis: Editora Vozes, 2018.

GOMES, Nilma Lino. O Movimento Negro no Brasil: ausências, emergências e a produção dos saberes. Política \& Sociedade, Santa Catarina, v. 10, n. 18, abr. 2011. p. 133-154.

GOMES, Nilma Lino (org.). Práticas pedagógicas de trabalho com relações étnico-raciais na escola na perspectiva da Lei 10.639/2003. Brasília, DF: MEC, UNESCO, 2012a.

GOMES, Nilma Lino. Relações étnico-raciais, educação e descolonização dos currículos. Currículos sem Fronteiras, v. 12, n. 1, p. 98-109, jan./abr. 2012b.

GROSFOGUEL, Ramón. La descolonización del conocimiento: diálogo crítico entre la visión descolonial de Frantz Fanon y la sociología descolonial de Boaventura de Sousa Santos. Formas-Otras, Barcelona, n. 1, p. 97-108, dez. 2011.

MBEMBE, Achille. Crítica da razão negra. Tradução de Sebastião Nascimento. São Paulo: N-1 Edições, 2018. 
MIGNOLO, Walter. Histórias globais/projetos locais: colonialidade, saberes subalternos e pensamento liminar. Belo Horizonte: Editora UFMG, 2003.

MOREIRA, Anália de Jesus. A Lei n. 10.639/03: pressupostos e propostas para a Educação Brasileira. In: SANTIAGO, Ana Rita et al. Descolonização do conhecimento no contexto afro-brasileiro. Cruz das Almas: EDUFRB, 2019. p. 63-73.

MUNANGA, Kabengele. Uma abordagem conceitual das noções de raça, racismo, identidade e etnia. In: BRANDÃO, André Augusto Pereira (org.). Cadernos Penesb nº 5. Niterói: EdUFF, 2004. p. 15-34.

NASCIMENTO, Abdias. O genocídio do negro brasileiro: processo de um racismo mascarado. São Paulo: Perspectivas, 2016.

NASCIMENTO, Abdias. O quilombismo. 2. ed. Brasília: Fundação Cultural Palmares; Rio de Janeiro: OR Editora, 2002.

PINA, Rute. Ensino de história da África ainda não está nos planos pedagógicos, diz professora. Brasil de Fato, São Paulo, 8 jan. 2017. Disponível em: https://www.brasildefato.com.br/2017/01/08/ensino-de-historia-da-africaainda-nao-esta-nos-planos-pedagogicos-diz-professora/. Acesso em: 29 jul. 2020.

QUIJANO, Aníbal. Colonialidad del poder y clasificación social. In: CASTRO-GÓMEZ, Santiago; GROSFOGUEL, Ramón (org.). El giro decolonial: reflexiones para una diversidad epistémica más allá del capitalismo global. Bogotá: Instituto Pensar: IESCO: Siglo del Hombre Editores, 2007. p. 93-126.

REIS, Diego dos Santos. O governo da emergência: estado de exceção, guerra ao terror e colonialidade. Rio de Janeiro: Multifoco, 2020a.

REIS, Diego dos Santos. A humanidade fabricada: identidade, violência e exclusão na construção do imaginário moderno/colonial. In: HADDOCK-LOBO, Rafael; AMITRANO, Georgia;RANGEL, Marcelo de Mello (org.). Rosas e pensamentos outros. Rio de Janeiro: Ape'Ku, 2020b. p. 199-211.

SANTOS, Boaventura de Sousa. A gramática do tempo: para um a nova cultura. São Paulo: Cortez, 2006.

SILVA, Ana Célia da. Ideologia do Embranquecimento. In: LIMA, Ivan Costa; BRANDÃO, Jeruse (org.). As ideias racistas, os negros e a educação. Florianópolis: Núcleo de Estudos Negros, 1997.

SILVA, Inayá Bittencourt e. Reflexões de uma trajetória em educação. Araraquara: Junqueira\&Marin, 2014.

SISS, Ahyas. Afro-brasileiros, cotas e ação afirmativa: razões históricas. Niterói: Quartet: PENESB, 2003.

SKERRETT, Allison. English teacher's racial literacy knowledge and practice, Race Ethnicity and Education, Abingdon, v. 14, n. 3, p. 313-330, 2011.

SOUZA, Elisabeth Fernandes de. Repercussões do discurso pedagógico sobre relações raciais nos PCNs. In: CAVALLEIRO, Eliane dos Santos (org.). Racismo e anti-racismo na educação: repensando nossa escola. São Paulo: Selo Negro, 2001.

WALSH, Catherine. Interculturalidad Crítica/Pedagogia decolonial. In: SEMINARIO INTERNACIONAL CULTURAS, DESARROLLOS Y EDUCACIONES (SICDES), 1., 2007, Bogotá. Anais [...]. Bogotá: Universidad Pedagógica Nacional, 2007.

WALSH, Catherine. Introducción: (re)pensamiento crítico y (de)colonialidad. In: WALSH, Catherine. Pensamiento crítico y matriz (de)colonial: reflexiones latinoamericanas. Quito: Ediciones Abya-yala, 2005. p. 13-35.

Data de submissão: 05/08/2020

Data de aceite: 14/10/2020 